\title{
UN LOTE DE CRISOLES TRIANGULARES MODERNOS EN SANLÚCAR DE BARRAMEDA
}

\author{
A COLLECTION OF MODERN TRIANGULAR CRUCIBLES \\ FROM SANLÚCAR DE BARRAMEDA (CÁDIZ)
}

\author{
por \\ FERNANDO DE AMORES CARREDANO \\ TOMÁS LLORET MARÍN
}

El objeto de esta nota es presentar una colección de crisoles de la Edad Moderna hallados casualmente en Sanlúcar de Barrameda (Cádiz). El interés estriba en documentar su presencia en España y llamar la atención sobre tales objetos para la arqueología de la Edad Moderna, por aumentar su conocimiento e interpretación.

Se trata de un conjunto de crisoles existentes en los fondos del Museo del Mar "Las Caracolas", curiosísimo museo privado sito en Sanlúcar de Barrameda '. El lote fue hallado por su dueño y director, D. Manuel Garrido al borde del agua en la playa de la desembocadura del Guadalquivir por donde pasea de continuo para recoger aquello que arroja y ofrece el mar.

El lote está compuesto por 10 crisoles de diferentes tamaños (fig. 1, lám. 1):

1.- 1 "mayor" que fue regalado a un amigo.

2.- $65 / 67 \mathrm{~mm}$ (lado triangular de la boca) por $68 \mathrm{~mm}$ (altura) y $30 \mathrm{~mm}$ (base): 4 ejemplares.

3.- $58 \times 58 \times 26 \mathrm{~mm} .: 2$ ejs.

4.- $49 \times 47 \times 26 \mathrm{~mm} .: 1$ ej.

5.- $40 \times 48 \times 20 \mathrm{~mm} .: 1 \mathrm{ej}$.

6.- 39 × $35 \times 20 \mathrm{~mm} .: 1$ ej.

Están confeccionados al torno, con forma cónica, base plana y boca triangular para verter por cualquiera de los picos. El material es de "gres" (cerámica cocida a altas temperaturas, casi vítrea), color gris o gris azulado con superficie granulosa (textura de piel de sapo) con engobe color claro, pajizo o gránulos anaranjados. Ninguno porta marca de fábrica ni señales de uso. Existen dos de tamaños consecutivos encajados de origen. Pudimos encajar a cuatro de tamaños consecutivos (lám. 2)

1. Desde aquí agradecemos a su dueño y director D. Manuel Garrido la amabilidad en prestarnos su tiempo y dedicación. Museo Las Caracolas, calle del Truco, 4 (Sanlúcar de Barrameda, Cádiz). 
Muy escaso en estudios, hemos tenido la fortuna de encontrar una sistematización básica de estos crisoles que tomamos como referencia (Cotter 1992). Este autor llama la atención sobre el escaso tratamiento dado en la literatura cerámica cuando, combinando fuentes arqueológicas y documentales, ha podido comprobar la importación a Inglaterra de miles de crisoles triangulares o de tipo "Hessian" (de Hesse) desde áreas de Alemania y Centro Europa en la Edad Moderna.

El tipo triangular de base plana se desarrolla como modelo más estable para hornos de trabajo permanentes desplazando a los medievales de base redonda. Los tamaños y formas están muy estandarizados y los de pequeño tamaño eran preferidos para trabajos con metales preciosos (oro y plata) y preparados químicos.

El origen parece situarse en Alemania en el s. XV habiendo sido conocido su existencia, función, orígenes y desarrollo gracias a representaciones gráficas o pictóricas en obras de los siglos XVI y $\mathrm{XVII}^{2}$, así como en la Enciclopedia de Diderot o la Metalurgia de Percy para el s. XIX. Este último autor cita a los crisoles de Hesse como triangulares y de venta en conjuntos (nidos) de seis. Parece que han sido utilizados hasta el s. XX sin diferencias en todos los centros industriales europeos.

Los ejemplos excavados en Inglaterra están asociados a contextos arqueológicos de los siglos XVIIXVIII y usos de farmacia, química, alquimia y preparación de esmaltes para cerámica. Un ejemplo de Bélgica del s. XVII se asocia con la fabricación de balas de plomo.

Los crisoles de Sanlúcar deben proceder de uno de los numerosos naufragios de barcos ocurridos cuando éstos chocaban contra la "barra" de Sanlúcar por temporales o falta de pericia para remontar el Guadalquivir hacia Sevilla (Vanney y Menanteau 1985). Las circunstancias del hallazgo, su asociación en un lote ${ }^{3}$, dos de ellos encajados, y la ausencia de señales de uso confirmarían este origen.

Desconocemos otros detalles del contexto original por lo cual no podemos aventurar otra datación que Modernos en general. Entendemos que su destino debió ser Sevilla cuando ostentaba el monopolio comercial con las Indias (ss. XVI-XVIII). El uso es bastante general como hemos podido ver, desde metalurgia de metales nobles, farmacia, química en general o alquimia. En los contextos excavados hasta el presente en Sevilla no han sido detectados aunque el desconocimiento existente sobre los mismos invalida toda valoración de su ausencia ${ }^{4}$.

Del máximo interés para esta presentación es el reciente hallazgo (1989-92) de crisoles triangulares (fragmentos y un ejemplar completo de $30 \times 32 \times 15 \mathrm{~mm}$ ) en excavaciones realizadas en La Isabela (República Dominicana) (Deagan 1992: 63-66). La Isabela es el primer asentamiento español en América. Fundado por Colón en el segundo viaje (1493-1496), es el único asentamiento colonial americano activo únicamente en el s. XV (1493-1498) (Deagan y Cruxent 1993). La autora relaciona

2. Cotter cita los grabados Melencolia de Durero (1514); Pirotechnia de Biringuccio (Venecia, 1540); De Re Metallica de Agrícola (Basilea, 1556); Beschreibung de Ercker (Praga, 1574) para el s. XVI. Las pinturas de la escuela flamenca del s. XVII gustaron de representar al alquimista en su taller donde aparecen a menudo los crisoles triangulares. Cotter cita a Jan Steen, Adriaen Van Ostade, Thomas Wijck y particularmente David Teniers el Joven del que recordamos una obra más de la serie referida por el autor, El Alquimista sito en el Museo del Prado. En cualquier caso es importante tener presente que estas representaciones hacen mofa de la alquimia, desacreditándola en un momento en que se desarrolla la química moderna (Hall 1987: 33). En uso estricto alquímico hemos recogido la curiosa representación de varios crisoles triangulares en la trasmutación de la materia en Speculum Veritatis (s. XVII, Biblioteca Apostólica Vaticana, Cod. lat. 7286, f. 13, recogido en Klossowski 1989: 55)

3. A este respecto, el lote de Sanlúcar se compone de seis tamaños diferentes, coincidente con las referencias a los lotes de venta en Percy.

4. Estando en redacción este artículo, tengo que agradecer al colega A. Pleguezuelo el conocimiento sobre un ejemplar completo hallado hace años en unas obras de construcción en Sevilla, sin otros detalles de su contexto. 
la presencia de crisoles con la metalurgia del oro, objetivo fundamental de la colonia, como lo atestiguan las actuaciones de los colonos en la isla y, arqueológicamente, el hallazgo de mercurio para el beneficio de la plata y el oro ${ }^{5}$. También existen evidencias de trabajo de plomo e hierro para balas y reparaciones varias, que no se asocian a estos crisoles sino a otros de mayor tamaño.

El segundo viaje de Colón fue cuidadosamente preparado en Sevilla, puerto de donde salieron, con 15 barcos, más de 1000 hombres y todos los pertrechos necesarios para un asentamiento colonial, incluidos especies animales y plantas. Por fuerza hemos de admitir que en la carga fueron incluidos los crisoles triangulares hallados en las excavaciones. Estos se habrían seleccionado como el instrumental más especializado para las pruebas y fundido de los metales aborígenes buscados. Las excavaciones de La Isabela han demostrado la temprana producción de cerámicas por los europeos in situ pero estos crisoles, cuando menos hasta el momento, son de "gres" centroeuropeo, portados por especialistas.

Es especialmente relevante admitir la importación de estos crisoles a Sevilla a fines del s. XV y su selección para la expedición americana. Evidentemente debían afluir con anterioridad a la ciudad para usos selectos de orfebrería, química y alquimia en general ${ }^{6}$ confirmándose una ruta marítima atlántica.

A partir de documentación textual es conocido el papel de Sevilla como puerto de distribución de mercancías al mundo atlántico, en mayor proporción a Southampton, Brujas y Amberes. El uso del oro para la acuñación de moneda en Sevilla, la exportación de oro africano y, a fines del s. XV, de mercurio para la amalgama de plata hacia centroeuropa nos interesa especialmente. Los agentes comerciales extranjeros radicados en Sevilla proporcionarían sin duda un intercambio con aquellas tierras que garantizarían la actualización tecnológica de los artesanos de la ciudad en lo relativo al trabajo con metales nobles (Otte 1996).

En cualquier caso, todo ello reflejaría una dependencia tecnológica de Sevilla, la mayor y más dinámica ciudad de Castilla en el s. XV, con respecto a centroeuropa para trabajos especializados a cambio de materias primas. Los contextos arqueológicos ponen de relieve detalles de singular trascendencia histórica no evidenciados en fechas tan tempranas hasta el momento en otros contextos arqueológicos europeos.

A este respecto tiene singular importancia el hallazgo de un crisol de tipo medieval, ovoide (123 $\mathrm{mm}$ altura x $65 \mathrm{~mm}$ de diámetro máximo), en el desecho del taller del ceramista italiano Francisco Niculoso Pisano (fig. 2) ${ }^{7}$ (Lorenzo y Vera 1987; Pleguezuelo 1992). Este hallazgo ${ }^{8}$, fechable en $1500-$ 1530, apunta a la diversidad de tradiciones en los usos de crisoles a partir de una diversificación tecnológica, reservando los triangulares para trabajos más especializados.

5. Sobre los avances en metalurgia provocados por la fiebre de metales preciosos en el s. XVI es ilustrativo el trabajo de (Fernández Vallín 1893: 111 y ss.)

6. El uso para alquimia está corroborado por las representaciones gráficas y pictóricas, pero éstas mismas también reflejan su uso metalúrgico debiendo considerar la relación de los crisoles triangulares con la alquimia como un uso más y no exclusivo. Los contextos arqueológicos hasta ahora demuestran un uso especializado en general.

7. La pieza (PU 609.3619), completa, está prácticamente metalizada en su totalidad, con adherencias de chorreos vitrificados de esmalte de cobre tanto al interior como al exterior. Al parecer ha sido usada repetidas veces para la fabricación de la "frita" o esmalte metálico para machacar con posterioridad y convertir en polvo.

8. Este crisol permanece inédito así como el estudio arqueológico del conjunto, de excepcional importancia, que esperamos estudiar y presentar más adelante. 


\section{BIBLIOGRAFÍA}

COTTER, J. P. (1992): “'The Mistery of the Hessian Wares'. Post- medieval triangular crucibles”. en Everiday and Exotic Pottery from Europe. Studies in honour of John G. Hurst, Oxbow Books, Oxford.

DEAGAN, K. (1992): Preliminary report on laboratory analysis of archaeological collections from La Isabela, Dominican Republic, 1989-1992. Mss.

y CRUXENT, J. M. (1993): From Contact to Criollos: The Archaeology of Spanish Colonization in Hispaniola, Proceedings of the British Academy, 81, pp. 67-104

FERNÁNDEZ VALLÍN, A. (1989): La cultura científica de España en el siglo XVI, Discursos leídos ante la Real Academia de Ciencias Exactas, Físicas y Naturales, Madrid, 1893. Reproducción por Padilla Libros, Sevilla.

HALL, J. (1987): Diccionario de temas y símbolos artísticos. Alianza Editorial, Madrid.

KLOSSOWSKI DE ROLA, S. (1989): Alquimia, ed. Debate, Madrid.

LORENZO, J. y VERA, M. (1987): "Informe-Memoria de las actividades arqueológicas realizadas en Calle Pureza 44 y Pelay Correa 15-17-19", Anuario Arqueológico de Andalucía, 1986, t. III, pp. 574-580, Sevilla.

MILANICH, J. T. y MILBRATH, S. eds. (1989): First Encounters. Spanish Explorations in the Caribbean and the United States, 1492-1570. University of Florida Press, Florida Museum of Natural History, Gainesville.

OTTE, E. (1996): Sevilla y sus mercaderes a fines de la Edad Media, Monte de Piedad y Caja de Ahorros de Huelva, Sevilla.

PLEGUEZUELO, A. (1992): "Francisco Niculoso Pisano: datos arqueológicos". Bolletino del Museo Internazionale delle Ceramiche in Faenza, fasc. III-IV: 171-191.

VANNEY, J-R. y MENANTEAU, L. (1985): "La Barra de Sanlúcar", en El Río. El Bajo Guadalquivir, Equipo 28, Sevilla, pp. 128-136. 

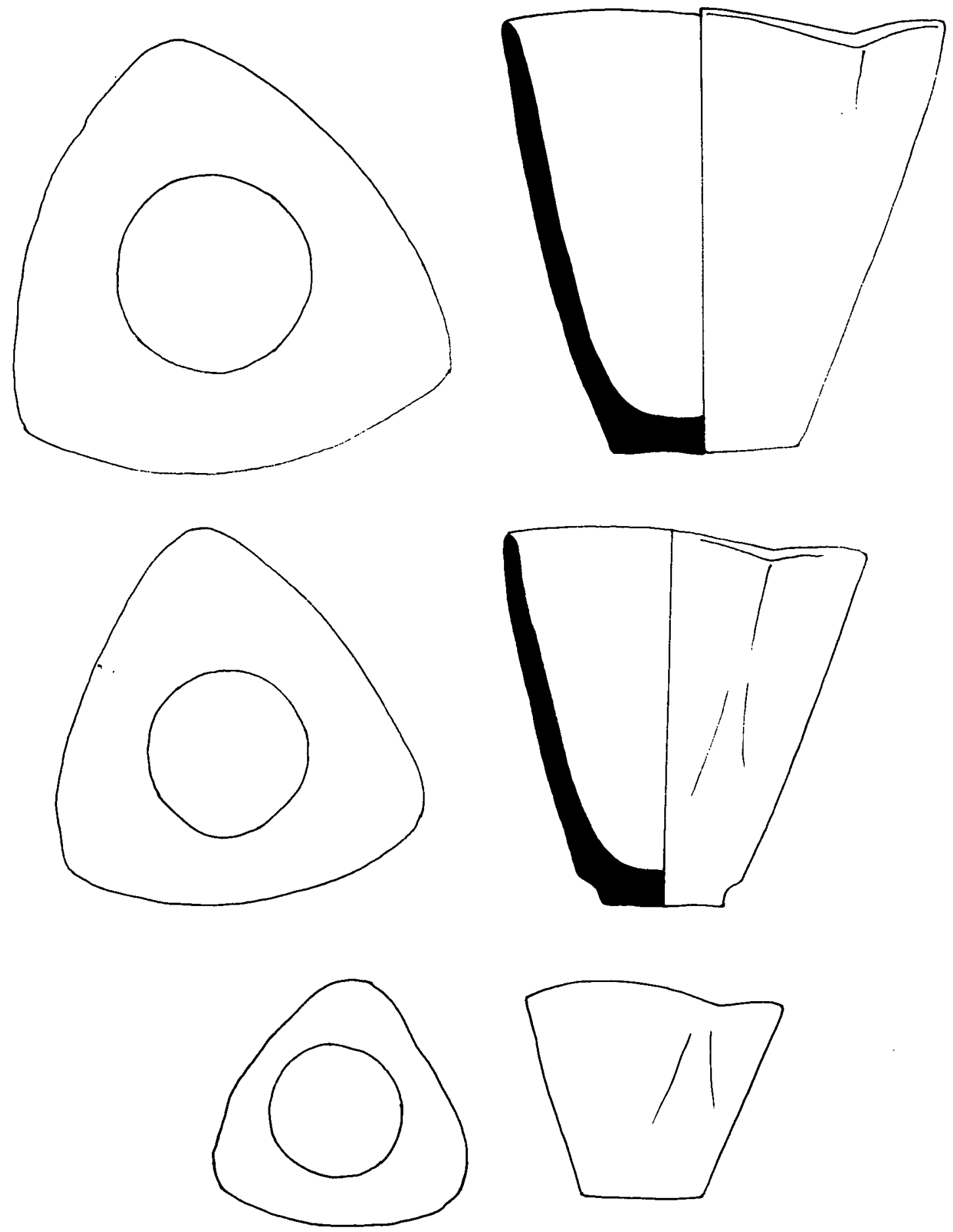

Fig. 1. Crisoles de Sanlúcar $\left(n^{\circ} 2,3,4,6\right)$ Vista desde la base y sección. 

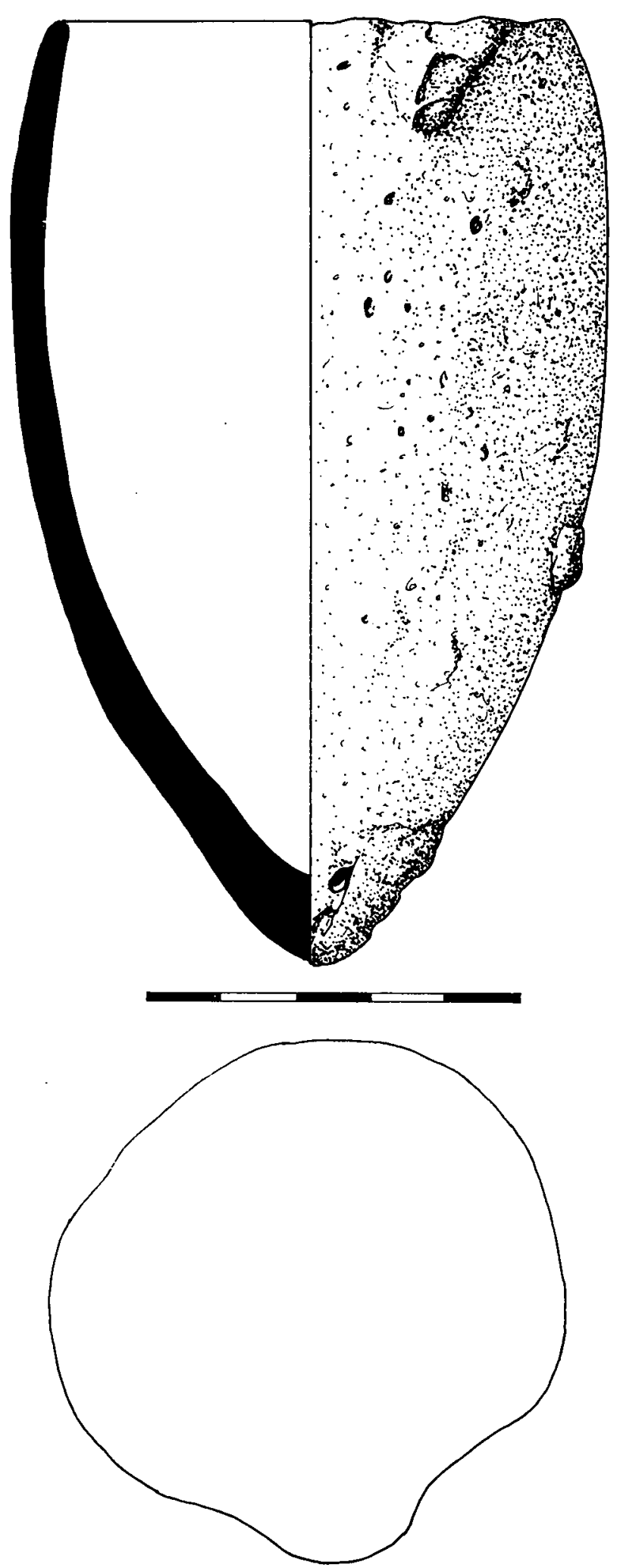

Fig. 2. Crisol de Pureza/44. 


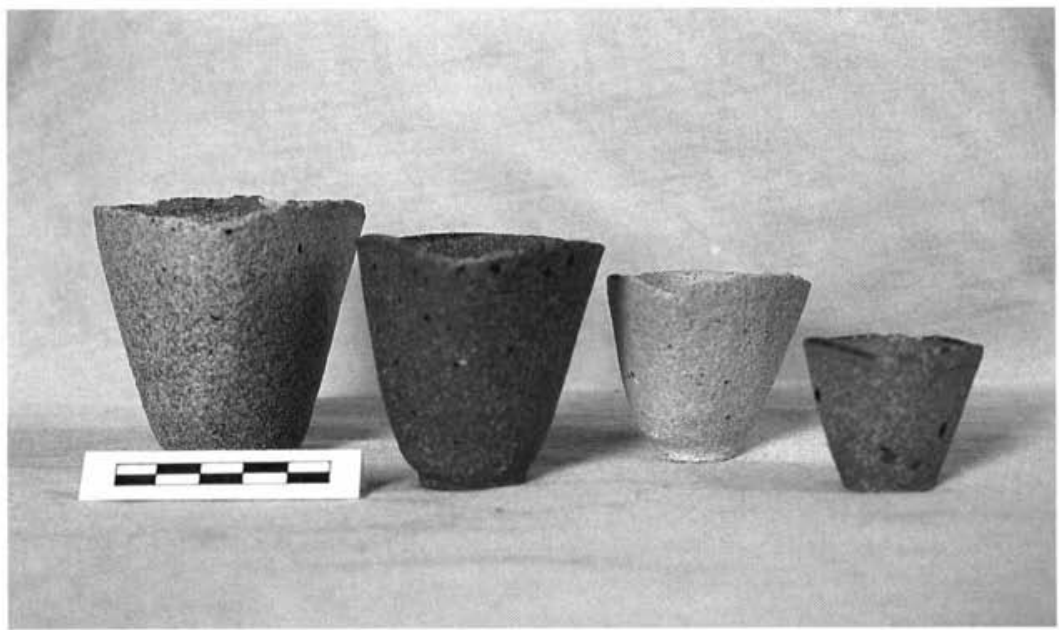

Lám. I. Conjunto de crisoles de Sanlúcar.

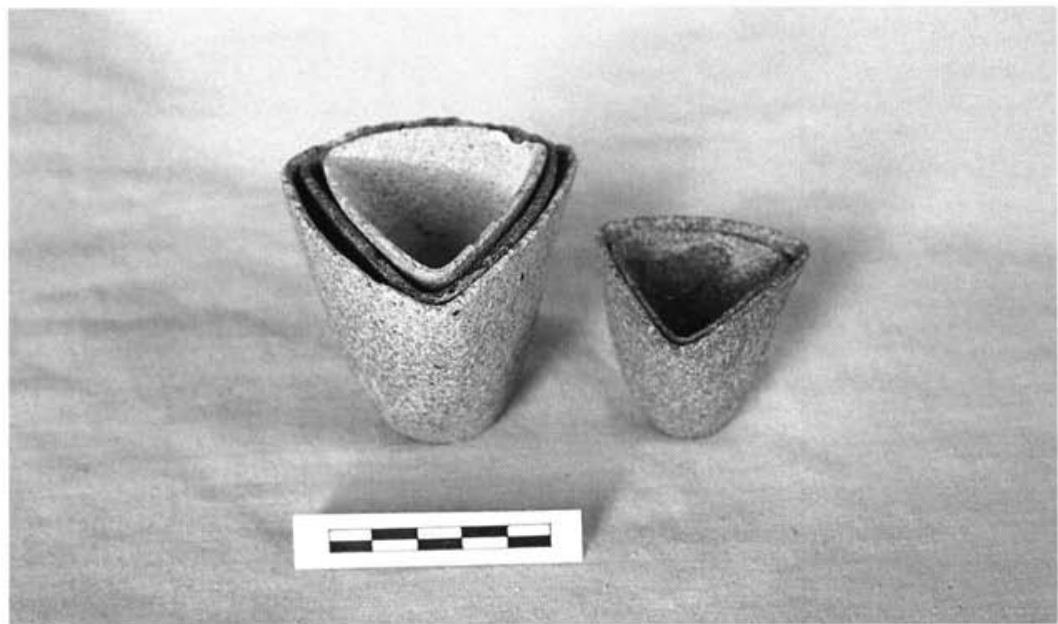

Lám. 2. Encaje de 4 crisoles.

ISSN: 1133-4525 ISSN-e: 2255-3924

http://dx.doi.org/10.12795/spal.1995.i4.12 